\title{
Subacute combined degeneration of the cord, dementia and Parkinsonism due to an inborn error of folate metabolism
}

\author{
PT CLAYTON, ISABEL SMITH, B HARDING, K HYLAND, JV LEONARD, \\ RJ LEEMING \\ From the Institute of Child Health and Hospital for Sick Children, London, and the General Hospital, \\ Birmingham, UK
}

SUMMARY A 2-year-old girl with 5,10-methylenetetrahydrofolate reductase deficiency developed subacute combined degeneration of the cord and a leuco-encephalopathy which was confirmed at necropsy. Total folate concentrations in serum, red cells and CSF were markedly reduced whereas vitamin B12 concentrations were normal. In addition the patient had Parkinsonism and reduced concentrations of homovanillic acid, 5-hydroxyindoleacetic acid and total biopterins in cerebrospinal fluid. Folic acid administration was accompanied by fits and acute deterioration in the movement disorder. At necropsy the basal ganglia showed no detectable abnormality.

Neurological problems occur rarely in patients with nutritional folate deficiency ${ }^{1}$ but rather more frequently in those who become folate deficient due to anti-convulsant therapy or alcoholism. ${ }^{23}$ Children with inborn errors of folate metabolism often present early in life with severe and progressive disease of the central nervous system (CNS).$^{45}$

This report describes a child with deficiency of 5,10-methylenetetrahydrofolate $\left(5,10 \mathrm{CH}_{2} \mathrm{THF}\right)$ reductase, the enzyme which converts $5,10 \mathrm{CH}_{2} \mathrm{THF}$ to 5-methyltetrahydrofolate $\left(5 \mathrm{CH}_{3} \mathrm{THF}\right)$ (fig 1 ). $5 \mathrm{CH}_{3} \mathrm{THF}$ is the methyl group donor for conversion of homocysteine to methionine ${ }^{16}$ in a reaction catalysed by 5-methyltetrahydrofolate; L-homocysteine methyltransferase, which requires a coenzyme derived from vitamin B12 as the intermediate methyl group carrier. ${ }^{14-6}$ So far as we are aware, the findings in our patient provide the first unequivocal evidence that an inborn error of folate metabolism causes subacute combined degeneration of the cord (SACD), and further support the view that defective turnover of $5 \mathrm{CH}_{3} \mathrm{THF}$ is the link between B12 deficiency and neurological disease. ${ }^{236-10}$

Address for reprint requests: Dr Isabel Smith, Institute of Child Health, Guilford Street, London WCIN IEH, UK.

Received 4 June 1985 and in revised form 24 October 1985. Accepted 2 November 1985

\section{Case report}

L. C. was born at term weighing $3030 \mathrm{~g}$. She developed normally during the first year of life but thereafter progress slowed. She did not walk until 18 months of age and at $21 / 4$ years she had only 6 or 7 words and no sentences. At this age she had a febrile illness with drowsiness and over the course of three weeks developmental regression occurred. She became ataxic, stopped walking, crawling, smiling and feeding herself and became incontinent. On examination her weight and length were on the 75 th centiles whereas head circumference was on the 3 rd centile. Head circumference at the age of 4 months had been on the 50th centile suggesting that impaired brain growth had developed after this age. She was withdrawn, immobile and apathetic, becoming more severely hypokinetic as her disease progressed. Her expression was mostly blank but she appeared frightened when disturbed. There were fine, semi-purposeful movements in the limbs and a Parkinsonian tremor in the arms with cogwheel rigidity and pill-rolling. The movement disorder and the level of social responsiveness fluctuated by the hour. When she could be persuaded to reach out for objects there was also a marked intention tremor. Fasciculation was visible in the muscles of the thigh and tongue and gross wasting was present in the small and large muscles of all limbs. Tone was increased in the legs which were held flexed at the knee and extended at the ankle. Tendon jerks were brisk and plantar responses were extensor; in the terminal stages of the illness ankle jerks were lost. There was a normal response to painful stimuli but it was not possible to assess sensory function more precisely. The optic discs and retinae were normal in all respects and so far as it could be tested vision was 


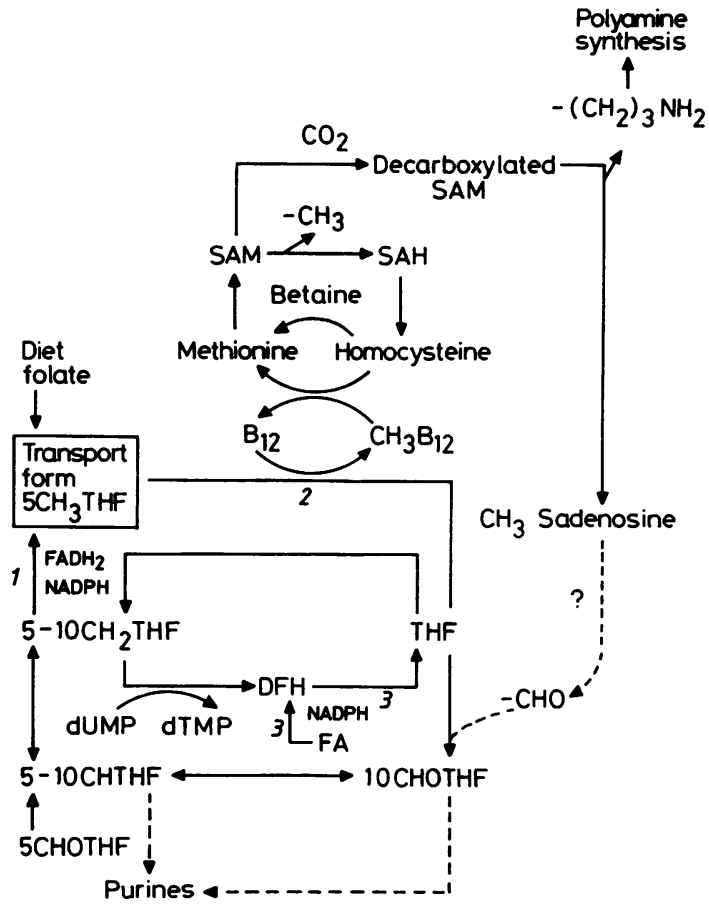

Fig 1 Simplified outline of folate turnover to illustrate conversion of 5,10-methylenetetrahydrofolate $\left(5,10 \mathrm{CH}_{2} \mathrm{THF}\right)$ to 5-methyltetrahydrofolate $\left(5 \mathrm{CH}_{3} \mathrm{THF}\right)$ and transfer of methyl groups $\left(-\mathrm{CH}_{3}\right)$ to homocysteine to form methionine. $T H F=$ tetrahydrofolate (tetrahydropteroylglutamic acid); 5,10CHTHF = 5,10-methenylTHF; 10CHOTHF =10-formylTHF; $5 C H O T H F=5$-formylTHF (folinic acid); $D H F=$ dihydrofolate; $F A=$ folic acid (pteroylglutamic acid); $S A M$ =s-adenosylmethionine; $S A H=s$-adenosylhomocysteine; $\mathrm{CH}_{3}$ Sadenosine $=$ methylthioadenosine; $\mathrm{NADPH}=$ reduced nicotinamide adenine dinucleotide phosphate; $\mathrm{FADH}_{2}=$ reduced flavine adenine dinucleotide; $d U M P=$ deoxyuridine monophosphate; $d T M P=$ deoxythymidine monophosphate. Enzymes; $1=5,10 \mathrm{CH}_{2} \mathrm{THF}$ reductase, 2 $=5 \mathrm{CH}_{3} \mathrm{THF} ;$ homocysteine methyltransferase, $3=\mathrm{DHF}$ reductase.

intact. Hearing also appeared to be normal. During administration of folic acid (see below) additional Parkinsonian symptoms, consisting of titubation, drooling and severe, continuous rhythmic tremor, were prominent and a series of myoclonic epileptic attacks occurred.

\section{Methods}

Plasma and urine amino acids, urine methylmalonic acid, haemoglobin and red cell indices were measured using standard techniques. Total folates in plasma, red cells and CSF were assayed using Lactobacillus casei. An assessment of the proportion of non-methyl folates was obtained by additional assays using Streptococcus fecalis and Pediococcus cerevisiae (Dr Jan Perry, Harrow). Serum B12 was assayed using Lactobacillus leishmanii. Total biopterin was assayed in dried blood spots, plasma and CSF using Crithidia fasciculata $^{11}$ which provides a measure of the combined activity of tetrahydrobiopterin $\left(\mathrm{BH}_{4}\right)$, dihydrobiopterin and biopterin. Confirmation of the Crithidia results was obtained by pterin analysis on urine and CSF using high performance liquid chromatography (HPLC) with fluorimetric detection (Dr A Niederwieser, Zurich). ${ }^{12}$ CSF obtained by lumbar puncture was divided as follows: the first $0.5 \mathrm{ml}$ was reserved for measurement of homovanillic acid (HVA) and 5-hydroxyindoleacetic acid (5HIAA) using HPLC with electrochemical detection, and the second $0.5 \mathrm{ml}$ for assay of total biopterin activity. ${ }^{13}$ The remainder was used for folate assays. Specimens were placed immediately on carbon dioxide ice in the dark and stored at $-70 \mathrm{C}$. Control values for amine metabolites and biopterins were obtained from 16 children without movement disorder who were being investigated for severe mental retardation. Activity of $5,10-\mathrm{CH}_{2}$ THF reductase was assayed in cultured skin fibroblasts (Dr B Fowler, Manchester).

\section{Results}

\section{Amino acids}

The urine consistently contained homocysteine and plasma concentrations ranged from the lower limit of detection $(4 \mu \mathrm{mol} / \mathrm{l})$ to $39 \mu \mathrm{mol} / \mathrm{l}$ (table). Plasma methionine concentrations fluctuated (11 to 36 $\mu \mathrm{mol} / \mathrm{l})$ within the low normal range. Methylmalonic acid was not detected.

\section{Folates}

At presentation total folate levels in serum, red cells and CSF were markedly reduced (table). Serum B12 was normal $(627 \mu \mathrm{g} / \mathrm{l})$. Despite the low red cell folate levels haemoglobin (13 g), mean cell volume (86 fl), and a blood film were normal, and remained so even in the terminal stages of the illness. Activity of $5,10 \mathrm{CH}_{2} \mathrm{THF}$ reductase was undetectable in cultured fibroblasts.

Following treatment with different species of folate (see table and later section) total folate levels rose, to the normal range and above in serum and red cells, and eventually towards the lower limit of normal in CSF (highest value $13 \cdot 2 \mu \mathrm{g} / \mathrm{l}$ ). Differential assay of the folate species revealed however that between 5 and $50 \%$ of red cell, serum and CSF folates were nonmethyl derivatives. Terminally CSF total folate fell again to low levels despite continuing folate therapy.

\section{Biopterins and amine metabolites}

Total biopterin activity in a series of dried blood spots was in the high normal range (table) and a single plasma value was normal $(1 \cdot 7 \mathrm{ng} / \mathrm{ml})$. CSF biopterins were consistently below the values obtained in controls (table). Analysis of urine and CSF pterins by HPLC showed that urine total biopterin (3.37 
Table Serial investigations from admission onwards in a patient with 5,10 methylenetetrahydrofolate reductase deficiency

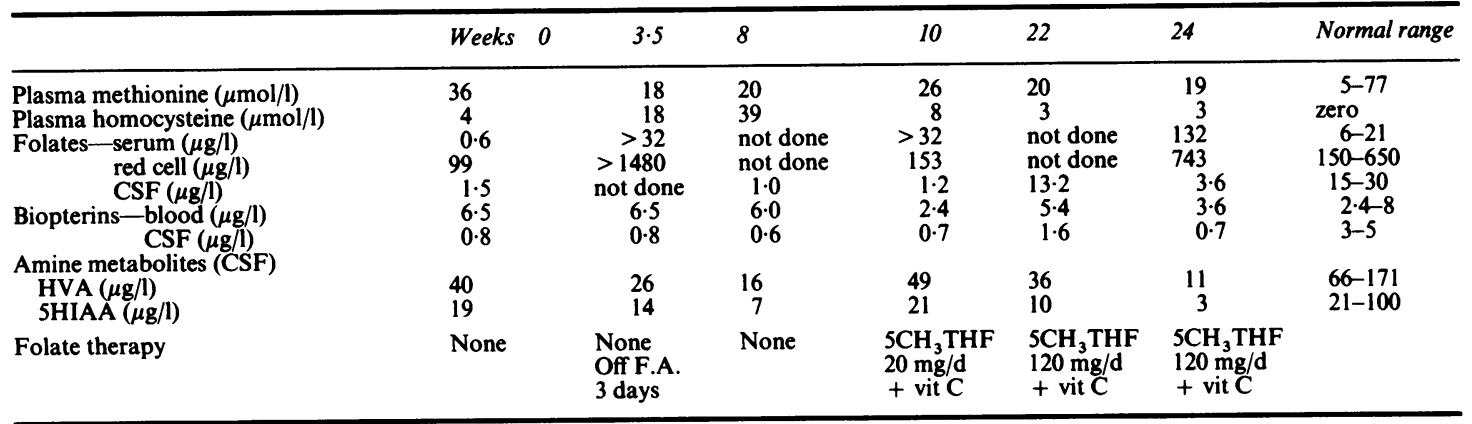

F.A. = Folic Acid.

$5 \mathrm{CH} \overrightarrow{\mathrm{T}}_{3} \mathrm{HF}=5$ methyltetrahydrofolate.

$\mathrm{mmol} / \mathrm{mol}$ creatinine, normal 0.7 to 1.9$)$ and total neopterin $(1.65 \mathrm{mmol} / \mathrm{mol}$ creatinine, normal 0.4 to $1.7 \mathrm{mmol}$ ) were high normal and consistent with the results of whole blood biopterins. CSF total biopterin $(1.9 \mu \mathrm{g} / \mathrm{l}$, normal 2.4 to $6 \mu \mathrm{g} / \mathrm{l})$ and total neopterin $(1.4$ $\mu \mathrm{g} / 1$, normal $2 \cdot 5$ to $5 \mu \mathrm{g} / \mathrm{l})$ were, like the Crithidia values, moderately reduced.

At diagnosis and subsequently CSF concentrations of HVA and 5HIAA were below control values. Terminally, when metabolite concentrations were at their lowest (table), therapy with levodopa, 5-hydroxytryptophan and carbidopa was introduced. This resulted in a prompt rise of amine metabolites to the normal range (HVA $95 \mu \mathrm{g} / 1$, 5HIAA $19 \mu \mathrm{g} / \mathrm{l}$ ) but no clinical improvement.

\section{Neurophysiological and radiological studies}

EEG findings (Drs Ann Harden, $S$ Boyd). The first EEG at 2 years 7 months showed generalised, moderate amplitude $1-4 \mathrm{~Hz}$ activity and absence of any normal rhythms. Occasional isolated, generalised discharges occurred. A further six EEGs over the next 5 months showed some decrease in amplitude of generalised slow components.

Flash visual evoked potential (VEP) studies At 2 years 7 months the electroretinogram was normal and remained so even in the late stages of the illness. Earlier components (before $100 \mathrm{~ms}$ ) of the mid-occipital VEP were poorly defined, indicating impaired function in the visual pathways and/or cortex. Follow-up studies at 2 years 11 months showed some increase in the latency of the earlier components suggesting further deterioration.

Brain stem auditory evoked potential (BAEP) studies At 2 years 11 months there was a markedly prolonged I/V interval of $5.62 \mathrm{~ms}$ compared with an upper limit of normal of $4.21 \mathrm{~ms}$ suggesting impaired function of auditory pathways through brain stem structures. A follow-up study 3 weeks later showed further-increase: of the $\mathrm{I} / \mathrm{V}$ interval to $5.88 \mathrm{~ms}$.
Electromyography (Dr J Payan) On sampling the right tibialis anterior and vastus medialis with a fine concentric needle electrode profuse, positive, sharp wave activity and fibrillation were found at several sites in both muscles. Voluntary motor unit potentials were of normal amplitude but showed a mild increase in polyphasia. No gross deviation from normal mean duration was detected. The left sural nerve sensory action potential and the right median nerve mixed nerve action potential were of normal amplitude, form and latency (sural $50 \mu \mathrm{V}$, median $85 \mu \mathrm{V}$ respectively). Maximum motor conduction velocity was reduced in left medial popliteal and right median nerves (30 and $38 \mathrm{~m} / \mathrm{s}$ respectively), and the evoked surface-recorded abductor hallucis muscle action potential was of reduced amplitude $(1 \mathrm{mV}$ negative phase). The findings suggested fall-out of large, fastconducting motor fibres due to a disorder at cord level, although the motor unit potentials were not typical of anterior horn cell damage.

Computed tomography ( $\mathrm{Dr} B$ Kendall) There was enlargement of the third and lateral ventricles with widening of the supratentorial space which, given the small head size, indicated cerebral atrophy. There was also ill defined low density in the white matter of both cerebral hemispheres.

\section{Response to therapy}

Initially the patient received a combination of folic acid ( $20 \mathrm{mg} /$ day), methionine (1 g/day), vitamin B12 $(1 \mathrm{mg} /$ day) and carnitine $(3 \mathrm{~g} /$ day $)$. Over 8 days she developed myoclonic epilepsy with deterioration in the EEG, and an acute Parkinsonian crisis including whole body tremor, drooling and rigidity. Treatment was withdrawn and the additional symptoms disappeared over the course of a week. Three days after withdrawal of folic acid CSF amine metabolite concentrations were lower than at diagnosis (table). $5 \mathrm{CH}_{3}$ THF $(20 \mathrm{mg} / \mathrm{day})^{-}$was then introduced alone. There was no exacerbation of symptoms and initially 
there appeared to be some improvement. After three weeks treatment was withdrawn during an attack of chickenpox. Re-examination of CSF HVA and 5HIAA concentrations two weeks after recovery showed that they were even lower than before and they rose again on reintroduction of $5 \mathrm{CH}_{3} \mathrm{THF}$. Six months therapy with up to $120 \mathrm{mg} 5 \mathrm{CH}_{3} \mathrm{THF} /$ day (given with ascorbic acid to prevent oxidative destruction) failed however to arrest neurological deterioration or to prevent amine metabolites falling to very low values. Terminally the patient developed recurrent fits and hypoventilation and she died just before her 3rd birthday.

\section{Neuropathology}

At necropsy there were no significant abnormalities except in the CNS. The brain was very small (unfixed

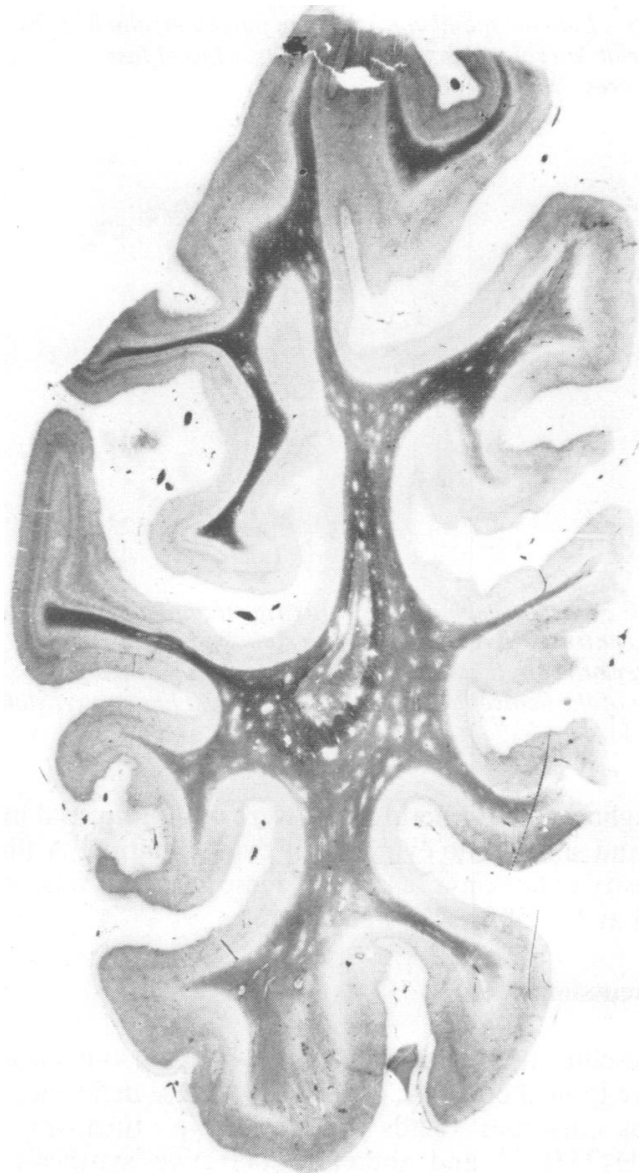

Fig 2 Histological section of occipital lobe showing small discrete perivascular foci of demyelination. (Luxol fast blue-cresyl violet $\times 2 \cdot 7$ ). weight $=662 \mathrm{~g}$, normal for age $1140 \mathrm{~g}$ ) and firm with prominent gyri. Coronal slices revealed slight ventricular dilatation but normal cortex, basal ganglia and brain stem. The white matter was very firm and showed occasional punctate cavities. Cerebellar white matter in the folia appeared slightly thin and the spinal cord seemed flattened with greyish posterior columns.

Histologically the most prominent pathological changes occurred throughout the white matter. In the subcortical and central cerebral white matter, the corpus callosum, capsules, fornix, optic nerves and tracts there were numerous, small usually perivascular foci of demyelination (fig 2). Myelin staining stopped abruptly at the edge of these zones within which there were numerous macrophages, hypertrophic fibre forming astrocytes and well preserved axons (fig $3 \mathrm{a}$ and b). These perivascular lesions coalesced into a larger area of demyelination in the centrum semi-ovale (fig 4). Some blood vessels in areas of normal myelin were
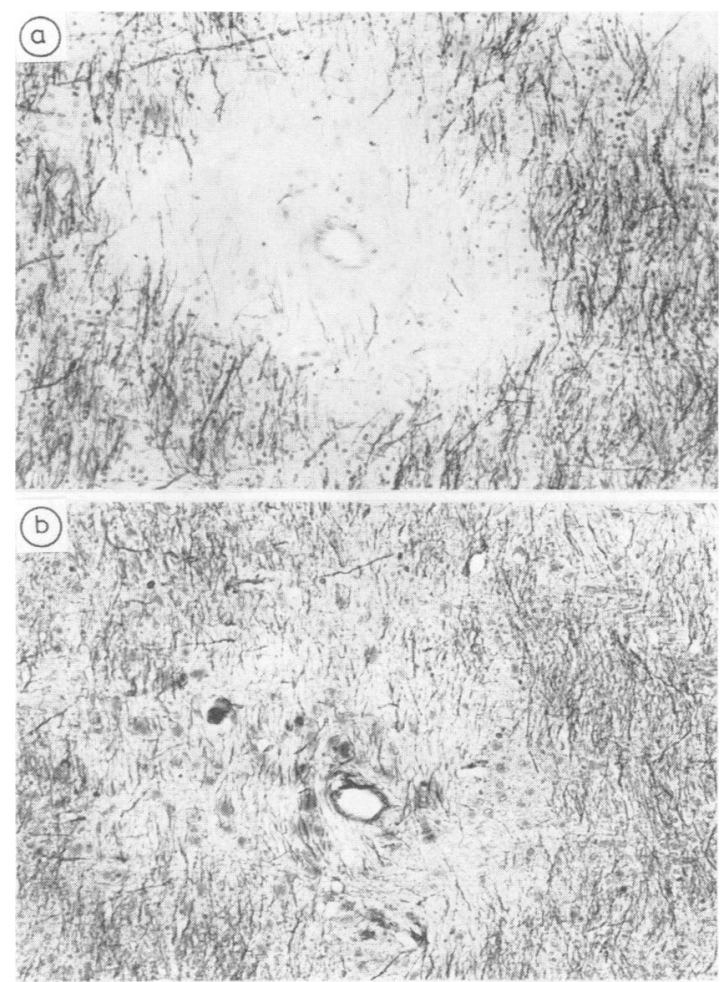

Fig 3 (a) Focal perivascular demyelination in the centrum semi-ovale. Myelin staining stops abruptly at the edge of the lesion which contains numerous hypertrophic astrocytes. (Luxol fast blue-cresyl violet $\times 360)$. (b) Adjacent section to fig 2 (Glees-Marsland silver impregnation). Axons are relatively well preserved within the demyelinated area $(x$ 360 ). 
also cuffed by mononuclear cells, but no vasculitis or thrombosis was present. There was diffuse mild neuronal loss and gliosis in the deeper layers of the cerebral cortex and also the hippocampus. Thalamus, basal ganglia and substantia nigra were normal. Demyelination was patchy in the brain stem but more severe in the cerebellar white matter. Cerebellar cortex was normal.

The white matter of the spinal cord was particularly severely affected: coalescence of demyelinated patches in anterior, lateral and posterior columns gave the typical appearance of subacute combined degeneration (fig 5). The lesion was most extensive in the thoracic cord (fig 6). At the margins of the demyelinated areas myelin sheaths showed spongy degeneration. There was accompanying gliosis but preservation of axons in all but the most severely degenerated regions. Spinal grey matter, in particular anterior horn cells, appeared normal. Dorsal root

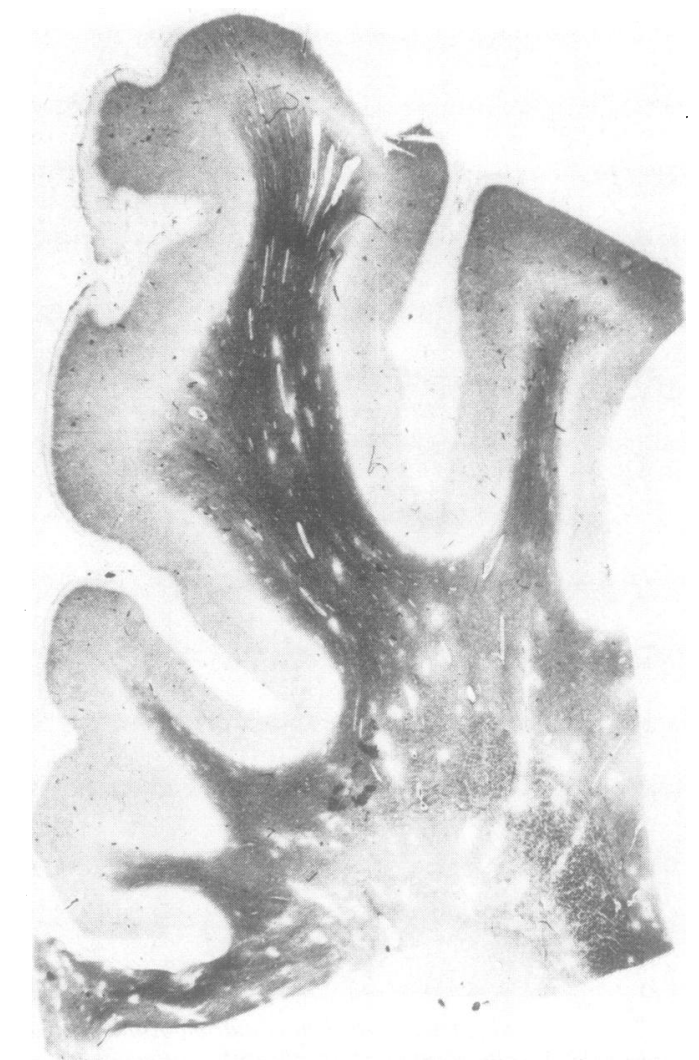

Fig 4 Histological section of frontal lobe. Focal myelin loss in corpus callosum and frontal white matter with coalescence of the lesions in the centrum semi-ovale. (Luxol fast blue-cresyl violet $\times 2 \cdot 7$ ).

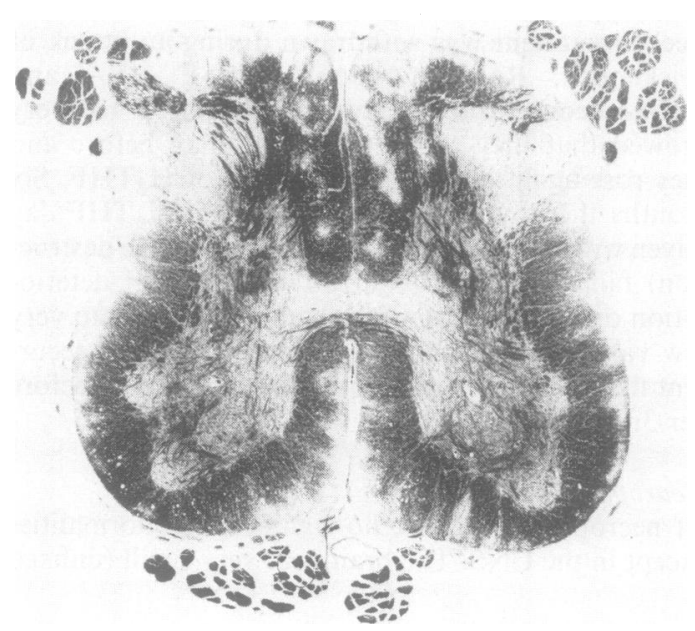

Fig 5 Lumbar spinal cord showing patchy myelin loss from anterior lateral and posterior columns. (Luxol fast blue-cresyl violet $\times 12 \cdot 3$ ).

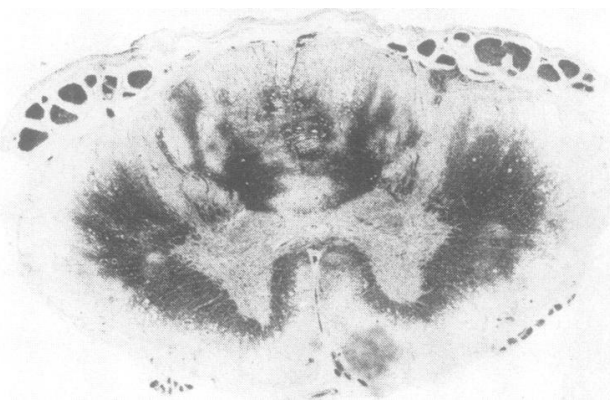

Fig 6 Thoracic spinal cord. Massive circumferential myelin loss contrasts with normal myelin staining in anterior and posterior roots. There is spongy degeneration at the inner edge of the demyelinated areas. (Luxol fast blue-cresyl violet $\times 15$ ).

ganglia and peripheral nerve were within normal limits and showed no evidence of demyelination. A fibre density count on a fascicle of femoral nerve was normal at $12150 / \mathrm{m}$ (Dr J Jacobs).

\section{Discussion}

The clinical and biochemical findings in our patient were typical of 5,10- $\mathrm{CH}_{2}$ THF reductase deficiency. ${ }^{45}$ This disorder leads to defective turnover of $5 \mathrm{CH}_{3} \mathrm{THF},{ }^{14}$ and therefore defective synthesis of methionine from homocysteine (fig 1). In addition $5 \mathrm{CH}_{3} \mathrm{THF}$ monoglutamate is the transport form of folate 1515 and is preferentially taken up across the 
blood-brain barrier. ${ }^{15}$ Normally most of the folate measured by the Lactobacillus casei assay in red cells, serum and $\mathrm{CSF}$ is $5 \mathrm{CH}_{3}$ THF. ${ }^{1}$

The patient described here is of particular interest since she died of subacute combined degeneration of the cord and a diffuse leuco-encephalopathy. During life the clinical features, CT scan appearance and deteriorating EEG and evoked potential studies (particularly the increasing $1 / v$ interval of the BAEP) were compatible with progressive demyelination. At necropsy the neuropathological lesions were indistinguishable from those found in patients dying of vitamin B12 deficiency. Although less frequent than cord lesions, extensive brain changes have been described in vitamin B12 deficiency, ${ }^{16}{ }^{17}$ and take the form of small perivascular foci of demyelination similar to the lesions in our patient. Detailed neuropathological description of B12 deficiency in children is lacking, but focal perivascular demyelination has been described in the cerebral white matter of a child with an inborn error of B12 metabolism. ${ }^{18}$

The severity of the myelin loss, particularly in thoracic cord, contrasted strikingly with minimal changes in neuronal cell bodies and axons, and with the normal myelination of nerve roots and peripheral nerve. The clinical and electrophysiological signs of muscle denervation and the reduced maximum motor conduction velocity, combined with the normal histology of peripheral nerve and anterior horn cells, we conclude were due to demyelination within the spinal cord of the axonal outflow from anterior horn cells.

In the previous post-mortem study of a patient with $5,10 \mathrm{CH}_{2} \mathrm{THF}$ reductase deficiency spinal cord findings were not reported. ${ }^{19}$ However, the cerebral lesions, although not identified as those of subacute combined degeneration did consist of patchy perivascular and confluent demyelination with moderate astrocyte hypertrophy as in the present case. Intimal damage with secondary thrombotic changes, such as occurs in association with homocystinuria due to cystathionine sythetase deficiency, was also reported to be present. ${ }^{19}$ The lack of vascular lesions in the present case emphasises that thrombotic damage is not an essential part of the pathogenesis of the neurological disease.

The findings reported here are consistent with the view that subacute combined degeneration is the result of defective turnover of $5 \mathrm{CH}_{3} \mathrm{THF}^{2367910}$ Such a defect, whether due to deficiency of methyl B $12^{20}$ or to defective folate metabolism, ${ }^{14}{ }^{19}$ might be expected to reduce turnover of methionine, sadenosylmethionine (SAM) and their derivatives ${ }^{8-10}$ as well as folates (fig 1). SAM is required in numerous transmethylation reactions. It is also the precursor of decarboxylated SAM, which is required in polyamine synthesis, ${ }^{21}$ and of 5,methylthioadenosine which recent work suggests may have an important role as a source of 1 carbon groups in conversion of tetrahydrofolate (THF) to 10 -formyltetrahydrofolate (10CHOTHF). ${ }^{22}$ The latter is probably the substrate required for synthesis of folate polyglutamates, the form in which most folate cofactors are active in intermediary metabolism.

The idea that defective turnover of methionine plays an important part in the pathogenesis of subacute combined degeneration is supported by animal studies showing that methionine administration prevents neurological lesions induced by nitrous oxide. ${ }^{9}$ In addition clinical studies of patients with $5-10 \mathrm{CH}_{2}$ THF reductase deficiency, have shown that neurological deterioration can be halted or even reversed, either by a combination of folinic acid, methionine and $\mathrm{B} 12,,^{2324}$ or by administration of large doses $(20 \mathrm{~g} /$ day $)$ of betaine. ${ }^{25}$ Betaine is able to methylate homocysteine to form methionine in the liver in the absence of $5,10 \mathrm{CH}_{2} \mathrm{THF}$ reductase. ${ }^{15}$ Although betaine itself may not enter the CNS, methionine and SAM $^{26}$ do move across the bloodbrain barrier, thus providing a mechanism whereby turnover of these compounds could be increased within the CNS as well as in the periphery by betaine therapy.

Patients with $5,10-\mathrm{CH}_{2}$ THF reductase deficiency, despite low serum and red cell folate concentrations, do not develop haematological complications or other signs of peripheral folate deficiency. ${ }^{145}$ In our patient peripheral nerves were normal even though CNS disease was so severe. Such disparity between peripheral and CNS disease is a well recognised feature of B12 deficiency. It seems likely that limited but adequate turnover of $5 \mathrm{CH}_{3} \mathrm{THF}$, and/or other methyl group donors, is maintained in peripheral tissues, perhaps via dietary sources of $5 \mathrm{CH}_{3} \mathrm{THF}$, choline, B12 and methionine, and by betaine-dependant hepatic turnover of methionine and SAM. The slow onset of neurological symptoms in our patient and others 4527 suggests that limited turnover of $5 \mathrm{CH}_{3} \mathrm{THF}$ is, at least for a time, also maintained in the CNS. Ultimately myelinated structures in brain and spinal cord prove more vulnerable to deficiency of $5 \mathrm{CH}_{3} \mathrm{THF}$ than peripheral tissues, perhaps because of a greater dependance on plasma $5 \mathrm{CH}_{3}$ THF concentrations (for passage of folate and methyl groups across the blood-brain barrier), ${ }^{15}$ and/or a greater requirement for methionine and its derivatives.

Acute neurological deterioration followed folic acid therapy in our patient. This observation is of interest since similar deterioration may occur in patients made folate deficient by anti-convulsants ${ }^{28}$ and in patients who are deficient in B12. ${ }^{1}$ This effect of folic acid has sometimes been regarded as evidence against the view that a defect in folate metabolism is 
the cause of subacute combined degeneration. Folic acid is not however a natural folate but an oxidised (and therefore stable) pharmacological derivative of THF requiring dihydrofolate reductase (DHFR) for conversion to active folate (fig 1). ${ }^{1}$ Oral administration of folic acid leads to a rise of non-methyl folate in serum, ${ }^{29}$ and the neurological deterioration it causes might be due to inhibition of $5 \mathrm{CH}_{3} \mathrm{THF}$ transport across the blood-brain barrier. ${ }^{15}$ This explanation is supported by observations made in a patient with dihydropteridine reductase deficiency who was treated with folic acid having developed neurological deterioration due to folate deficiency ${ }^{30}$ In this patient 10 days' therapy with folic acid resulted in neurological deterioration and, despite a rise of total folates in serum and red cells, caused an actual fall in CSF folate as in the present case.

As well as dementia and long tract signs the patient reported here had Parkinsonism which was accompanied by reduced CSF concentrations of neurotransmitter amine metabolites, total biopterins and neopterins. Reduction of CSF amine metabolite concentrations has been observed in animals and human subjects with folate deficiency ${ }^{31}$ and in other patients with $5,10 \mathrm{CH}_{2}$ THF reductase deficiency ${ }^{13233233}$ but this is the first report of pterin disturbance. Tetrahydrobiopterin $\left(\mathrm{BH}_{4}\right)$ is an essential cofactor in the synthesis of catecholamines and serotonin, and neopterin triphosphate is the precursor of $\mathrm{BH}_{4}$ in vivo. ${ }^{4}$ The data suggest a close (but unexplained) link between folate and central amine metabolism supported by other observations. ${ }^{2633} 34$ In this context it is of interest that CNS concentrations of $5 \mathrm{CH}_{3} \mathrm{THF}$ are highest in serotonin producing nuclei. ${ }^{35}$

In contrast to CSF pterins peripheral pterin concentrations were high normal suggesting that the disturbance of pterin metabolism was, like the demyelination, confined to the CNS. Initially we were inclined to attribute the amine abnormalities to defective synthesis of $\mathrm{BH}_{4}$ from guanosine triphosphate (GTP) via neopterin, leading to defective hydroxylation of tyrosine to levodopa and tryptophan to 5-hydroxytryptophan. ${ }^{36}$ The latter are the rate limiting reactions of catecholamine and serotonin synthesis and patients with defective synthesis of $\mathrm{BH}_{4}$ are severely amine deficient. However folates inhibit pterin synthesis in vitro, ${ }^{37}$ and deficiency of THF induced by methotrexate increases rather than decreases biopterin synthesis, in vivo as well as in vitro, ${ }^{11} 3839$ making it unlikely that the amine disturbance was due to defective pterin synthesis.

In a patient with dihydropteridine reductase deficiency folate lack was accompanied by increasing movement disorder and amine deficiency despite therapy with levodopa and 5-hydroxytryptophan and, as in the patient described here, folic acid administration exacerbated neurological symptoms and reduced CSF concentrations of amine metabolites. The findings led us to suggest that deficiency of folate blocked the synaptic release of amines rather than their synthesis. ${ }^{30}$ The entirely normal appearance of the basal ganglia at necropsy reported here is consistent with this suggestion.

We conclude that defective methyl folate metabolism is the key to neurological damage in subacute combined degeneration, that the harmful effects of folic acid are evidence for, rather than against, this view and that defective amine turnover is a facet of the neurological disturbance. Treatment of patients with $5-10 \mathrm{CH}_{2} \mathrm{THF}$ reductase deficiency should be directed towards maintaining methionine turnover ${ }^{132325}$ as well as the supply of folate to the CNS. The pathogenesis of demyelination in subacute combined degeneration remains to be elucidated. Further characterisation of the neurochemistry and neuropathology of both inherited and acquired defects of folate metabolism should add to our understanding of this process.

We thank Drs B Fowler, A Niederwieser, Jan Perry, Ann Harden, S Boyd, J Payan and B Kendall for their generous help with the investigations, Dr JFB Dossetor for referring the patient to us and Prof JA Blair for helpful discussions. $\mathrm{KH}$ and IS are in receipt of financial support from the McAlpine Foundation, and the Medical Research Council respectively.

\section{References}

${ }^{1}$ Chanarin I. The Megaloblastic Anaemias. 2nd ed. Oxford: Blackwell Scientific Publications, 1979.

${ }^{2}$ Pincus JH. Folic acid deficiency. A cause of subacute combined system degeneration. In: Botez MI, Reynolds EH, eds. Folic Acid in Neurology, Psychiatry and Internal Medicine. New York: Raven Press, 1979: 427-33.

${ }^{3}$ Guard O, Dumas R, Audry D, Tommasi M, Knopf JF. Etude anatomo-clinique d'un cas de degenerescence combinée subaigue medullaire au cours d'une carence en acide folique. Rev Neurol (Paris) 1981;137:435-46.

${ }^{4}$ Niederwieser A. Inborn errors of pterin metabolism. In: Botez MI, Reynolds EH, eds. Folic Acid in Neurology, Psychiatry Internal Medicine. New York: Raven Press, 1979:349-84.

${ }^{5}$ Rowe PB. Inherited disorders of folate metabolism. In: Stanbury JB, Wyngaarden JB, Fredrickson DS, Goldstein JL, Brown MS, eds. The Metabolic Basis of Inherited Disease. New York: McGraw Hill Book Co, 1983:498-521.

${ }^{6}$ Nixon PF, Bertino JR. Inter-relationship of vitamin B12 and folate in man. Am J Med 1970;48:555-61.

${ }^{7}$ Reynolds EH. The neurology of vitamin B12 deficiency. Lancet 1976;2:832-3. 
${ }^{8}$ Jacobsen W, Gandy G, Sidman RL. Experimental subacute combined degeneration of the cord in mice. $J$ Pathol 1973;109 Abst 36, xii-xiv.

${ }^{9}$ Scott JM, Dinn JJ, Wilson P, Weir DG. Pathogenesis of subacute combined degeneration: A result of methyl group deficiency. Lancet 1981;2:334-7.

${ }^{10}$ Scott JM, Weir DJ. The methyl folate trap. Lancet 1981;2:337-40.

${ }^{11}$ Leeming RJ, Blair JA. Melikian V, O'Gorman DJ. Biopterin derivatives in human body fluids and tissues. $J$ Clin Pathol 1976;29:444-51.

12 Niederwieser A, Curtius H-Ch, Gitzelmann R, et al. Excretion of pterins in phenylketonuria and phenyketonuria variants. Helv Paediat Acta 1980;35:335-42.

${ }^{13}$ Hyland K, Smith I, Howells DW, Clayton PT, Leonard JV. The determination of pterins, biogenic amine metabolites and aromatic amino acids in cerebrospinal fluid using isocratic reverse phase liquid chromatography with in series dual cell coulometric electrochemical and fluorescence detection: use in a study of inborn errors of dihydropteridine reductase and 5,10-methylenetetrahydrofolate reductase deficiency. In: Wachter $\mathrm{H}$, Curtius $\mathrm{H}-\mathrm{Ch}$, Pfleiderer W, eds. Biochemical and Clinical Aspects of Pteridines. Vol 4. Berlin: Walter de Gruyter, 1985:85-99.

${ }^{14}$ Rosenblatt DS, Cooper BA, Lue-Shing S, et al. Folate distribution in cultured human cells. Studies on 5,10-CH2-H4, PteGlu reductase deficiency. J Clin Invest 1979;63:1019-25.

${ }^{15}$ Levitt M, Nixon PF, Pincus JH, Bertino JR. Transport characteristics of folates in cerebrospinal fluid; a study utilizing doubly labelled 5-methyltetrahydrofolate and 5-formyltetrahydrofolate. J Clin Invest 1971;50:1301-8.

${ }^{16}$ Duchen LW, Jacobs JM. Nutritional deficiencies and metabolic disorders. In: Adams JH, Corselis JAN, Duchen LW, eds. Greenfield's Neuropathology; 4th ed. London: Edward Arnold, 1984:573-626.

${ }^{17}$ Adams RD, Kubik CS. Subacute combined degeneration of the brain in pernicious anaemia. $N$ Engl $J$ Med 1944;231:1-9.

${ }^{18}$ Dayan AD, Ramsey RB. An inborn error of B12 metabolism associated with cellular deficiency of coenzyme forms of the vitamin. J Neurol Sci 1974;23:117-28.

${ }^{19}$ Kanwar YS, Manaligod JR, Wong PWK. Morphologic studies in a patient with homocystinuria due to 5,10-methylenetetrahydrofolate reductase deficiency. Pediatr Res 1976;10:598-609.

${ }^{20}$ Schuh S, Rosenblatt DS, Cooper BA, et al. Homocystinuria and megaloblastic anaemia responsive to vitamin B12 therapy. $N$ Engl J Med 1984;310:686-90.

${ }^{21}$ Tabor CW, Tabor H. Polyamines. Ann Rev Biochem 1984;53:749-90.

${ }^{22}$ Perry J, Chanarin I, Deacon R, Lumb M. Impaired pteroylpolyglutamate synthesis in the cobalamine inactivated rat. The effect of methionine, Sadenosylmethionine and 5-methylthioadenosine in correcting the defect. In: Blair JA, ed. Chemistry and Biology of Pteridines. Berlin: Walter de Gruyter, 1983:807-13.

${ }^{23}$ Harpey J-P, Rosenblatt DS, Cooper BA, Le Moel G, Roy C, Lafourcade J. Homocystinuria caused by 5,10-methylenetetrahydrofolate reductase deficiency: A case in an infant responding to methionine, folinic acid, pyridoxine and vitamin B12 therapy. $J$ Pediatr 1981;98:275-8.

${ }^{24}$ Harpey J-P, Le Moel G, Zittoun J. Follow-up in a child with 5,10-methylenetetrahydrofolate reductase deficiency. J Pediatr 1983:1007 (letter).

${ }^{25}$ Wendel U, Bremer HJ. Betaine in the treatment of homocystinuria due to 5,10-methylenetetrahydrofolate reductase deficiency. Eur J Pediatr 1984;142:147-50.

${ }^{26}$ Bottiglieri $\mathrm{T}$, Laundy $\mathrm{M}$, Martin $\mathrm{R}$, et al. $\mathrm{S}$-adenosylmethionine influences monoamine metabolism. Lancet 1984;2:224 (letter).

${ }^{27}$ Wong PWK, Justice P, Hruby M, Weiss EB, Diamond E. Folic acid nonresponsive homocystinuria due to methylenetetrahydrofolate reductase deficiency. Pediatrics 1977;59:749-56.

${ }^{28}$ Chanarin I, Laidlaw J, Loughridge LW, Mollin DL. Megaloblastic anaemia due to phenobarbitone; The convulsant action of therapeutic doses of folic acid. $\mathrm{Br} \mathrm{Med}$ J 1960;1:1099-102.

${ }^{29}$ Ratanasthien K, Blair JA, Leeming RJ, Cooke WT, Melikian V. Serum folates in man. J Clin Pathol 1977;30:438-48.

${ }^{30}$ Smith I, Hyland K, Kendall B, Leeming R. Clinical role of pteridine therapy in tetrahydrobiopterin deficiency. $J$ Inherit Metab Dis 1985;8 (suppl 1):39-45.

${ }^{31}$ Botez MI, Young SN, Bachevalier J, Gauthier S. Folate deficiency and decreased brain 5-hydroxytryptamine synthesis in man and rat. Nature 1979;278:182-3.

${ }^{32}$ Singer HS, Butler I, Rothenberg S, Valle D, Freemen J. Inter-relationships among serum folate, CSF folate, neurotransmitters and neuropsychiatric symptoms. Neurology (Minneap) 1980;30:419 (Abstract.)

${ }^{33}$ Allen RJ, Wong P, Rothenberg SP, DiMauro S, Headington JT. Progressive neonatal leucoencephalopathy due to absent methylene tetrahydrofolate reductase responsive to treatment. Ann Neurol 1980;8:211 (Abstract.)

${ }^{34}$ Chadwick D, Jenner P, Reynolds EH. Serotonin metabolism in human epilepsy: influence of anti-convulsant drugs. Ann Neurol 1977;1:218-24.

${ }^{35}$ Korevaar WC, Geyer MH, Knapp S, Hsu LL, Mandell AJ. Regional distribution of 5-methyltetrahydrofolic acid in brain. Nature 1973;245:244-5.

${ }^{36}$ Kaufman S. Regulatory properties of pterin dependant hydroxylases: variations on a theme. In: Usdin E, Weiner N, Youdim MBH, eds. Function and Regulation of Monoamine Enzymes. New York: MacMillan, 1981:165-73.

${ }^{37}$ Kapatos G, Kaufman S. Inhibition of pterin biosynthesis in the adrenergic neuroblastoma N1E115 by tetrahydrobiopterin and folate. In: Blair JA, ed. Chemistry and Biology of Pteridines. Berlin: Walter de Gruyter, 1983:171-5.

${ }^{38}$ Nichol CA, Lee CL, Edelstein MP, Chao JY, Duch DS. Biosynthesis of tetrahydrobiopterin by de novo and salvage pathways in adrenal medulla extracts, mammalian cell cultures and rat brain in vivo. Proc Nat Acad Sci USA 1983;80:1546-50.

${ }^{39}$ Pinkerton CR, Smith I, Leeming RJ, et al. Methotrexate therapy is not associated with neurotransmitter amine deficiency. $J$ Pediatr (in press). 